\title{
La negación de la representación como estrategia creativa del dividuo
}

\section{The denial of representation as a creative strategy of dividuo}

TIPO DE TRABAJO: Comunicación.

PALABRAS CLAVE

Negación, vacío, arte, dividuo.

KEY WORDS

Denial, void, art, dividuo.

\section{RESUMEN}

\begin{abstract}
Consideramos que en la actualidad el vacío en la creación plástica goza de una oportunidad idónea para legitimarse como categoría procesual singular. El sujeto de la hipermodernidad se mueve entre el deseo y la apariencia, y las ficciones sobre las que se construye están llenas de vacíos. Estos espacios por un lado son consecuencia de unas imágenes sin referencias orientadas a saciar el hambre del deseo; y por otro constituyen el deterioro y la depresión del sujeto. Ambas orientaciones, tanto la del vacío de la imagen como la del vacío del sujeto, pueden ser corregidas desde la activación y el entendimiento del vacío como una categoría creadora. En este sentido, las estrategias artísticas de reducción, ocultación, desmaterialización y resonancia permiten hacer del vacío una práctica creadora y constructora, no solo del imaginario, sino también de la identidad. Estas estrategias contextualizan lo que hemos denominado como vacío creador, que por un lado cuestiona el vacío generado por la pérdida de la identidad, y por otro, activa el reencuentro con la imagen de la sombra que nos pertenece. El vacío así entendido, permite un reencuentro con el espacio situado entre las cosas, con el recuerdo a través de la resonancia, de la memoria de lo que el sujeto es más allá de su apariencia. Sin tocarlo, nos acerca al mundo imaginario del acontecimiento y a los fragmentos que perduran de nuestra identidad con lo real. Entendemos que esta práctica sitúa al sujeto como un ente dividido y fragmentado, contrario a toda visión del mundo unitaria y totalizadora, y por tanto, como una realidad frágil pero llena de posibilidades. El vacío creador ofrece la posibilidad al sujeto de transformarse en posibilidad, en acontecimiento. Las estrategias del vacío en el arte son la mecha para la posibilidad de la dividualización, del ser potencia.
\end{abstract}

\section{ABSTRACT}

We consider that currently the vacuum in the plastic creation enjoys a suitable opportunity to legitimize itself as a singular process category. The subject of hypermodernity moves between desire and appearance, and the fictions on which it is built are full of voids. These spaces on the one hand are the result of images without references aimed at satisfying the hunger of desire; and on the other constitute the deterioration and depression of the subject. Both orientations, both that of the emptiness of the image and that of the emptiness of the subject; can be corrected from the activation and understanding of the void as a creative category. In this sense, the artistic strategies of reduction, concealment, dematerialization and resonance allow us to make of the vacuum a creative and constructive practice, not only of the imaginary, but also of the identity. These strategies contextualize what we have called creative void: which on the one hand questions the vacuum generated by the loss of identity, and on the other, activates the reencounter with the image of the shadow that belongs to us. The emptiness thus understood, allows a reencounter with the space located between things, with the memory through resonance, of the memory of what the subject is beyond its appearance. Without touching it, it brings us closer to the imaginary world of the event and to the fragments that remain of our identity with the real. We understand that this practice places the subject as a divided and fragmented being, contrary to any vision of the unitary and totalizing world, and therefore, as a fragile reality but full of possibilities. Creative emptiness offers the possibility to the subject to transform itself into possibility, into an event. The strategies of emptiness in art are the fuse for the possibility of dividualization, of being power. 


\section{INTRODUCCIÓN. El vacío en las artes plásticas}

La comunicación que presentamos a continuación es en parte el resultado de una investigación llevada a cabo recientemente y que finalmente vio la luz en la tesis doctoral: Estrategias creativas del arte frente a la dividualización. En este sentido, y en relación al lema que lleva por título esta IV edición del Congreso Internacional de Investigación en Artes Visuales que se celebra entre el 4 y 5 julio de 2019 en Valencia: "Imagen [n] visible"; creemos oportuno aprovechar esta circunstancia para poder compartir y valorar entre todos lo que hemos definido como la defensa del Vacío Creador en la producción artística, o lo que podríamos adelantar sería el posicionamiento del artista de negar la representación frente a la tendencia y proliferación de la imagen en la cultura actual.

Esta comunicación pretende así unirse al resto de prácticas de creación e investigación que desde las artes reflexionan, exploran, y experimentan no sólo las posibilidades expresivas de la visualidad, si no las de la no visualidad en el actual contexto que el espectador sufre de sobreexposición de imágenes.

VACíO DE LA IMAGEN
Naturaleza de la imagen digital
ACTIVACIÓN YY EL ENTENDIMIENTÓ DEL VACÍO
COMO UNA CATEGORÍA CREADORA
Hipermodernidad

Tabla 1 Contexto del Vacío como recurso creativo. Fuente propia.

Nosotros entendemos por negación de la representación aquellas estrategias creativas que producen un distanciamiento entre la realidad y su imagen, o siguiendo la línea de trabajo del investigador Hernandez Navarro: estrategias creativas de reducción de lo que hay para ver, de ocultación del objeto visible y desmaterialización de la obra. Estaríamos en definitiva frente a un proceso de distanciamiento, interposición, retardo y ocultación entre realidad e imagen, son estrategias que están en relación con el pensamiento de la antivisión (Krauss, 1986) y la desmaterialización (Lippard, 1973).

Podemos pensar que la invisibilidad se hizo presente en la práctica artística contemporánea partiendo de lo que Ulrike Lehman junto a Peter Weibel denominaron la estética de la ausencia (Butin, 2009). Para la crítica y comisaria Ulrike Lehmann, a las artes plásticas siempre acompañó un movimiento dialéctico entre presencia y ausencia (Lehmann, 2009) y afirma:

"Siempre han existido en nuestra cultura acciones cúlticas de ocultar y descubrir imágenes como objetos en templos sólo mostrados en ocasiones con el objetivo de destacar su singularidad y atraer mayor atención. La imagen estaba presente, pero no era visible. Estas eran formas de ausencia o incluso de destrucción iconoclástica que obedecían casi siempre a motivos religiosos o políticos. Fueron estas estrategias que hacían desaparecer la imagen propia cubriéndola o haciéndola invisible incluso destruyéndola para volver a generarla de otra manera. Manifestaciones artísticas que podríamos situar en una zona de la visión que pertenece al mundo del espacio entre las cosas. Entre ser y apariencia, presencia y ausencia. En este proceso el ser es determinado por aquella obra «nueva» y su materialidad, que tematizan la ausencia. La apariencia es sugerida por la obra de arte ausente".

Rudolf Arnheim, psicólogo de la percepción, hablará de huecos visibles. Ver el vacío es incluir en una percepción algo que le pertenece, pero que está ausente; es ver la ausencia de eso que falta como una cualidad de lo presente (Arnheim, 1985). De este modo dominios que están en el límite de la percepción se tornan experimentables aunque la expectativa que tiene el espectador de ver una imagen es inicialmente negada. Se trata de un diálogo entre obra y espectador aparentemente imposible, las imágenes están y no están (Lehmann, 2009). Sin embargo, estas obras nos invitan a confiar en la fantasía e invocar imágenes almacenadas en nuestra memoria. En casos, los espectadores: se convierten en cómplices, invitándoseles a abandonar su papel pasivo y tornarse activos. Ulrike Lehmann y Peter Weibel clasificaron estas estéticas de la ausencia de la siguiente manera: imágenes reproducidas, imágenes que desaparecen, imágenes archivadas, ocultas, autorreferenciales, vacías, inmateriales, imágenes que se disuelven, destruidas e imágenes del el espacio vacío (Dornbuscch, 2011).

Ha habido una estética de la ausencia desde comienzos del siglo XX. Ya en el XIX las primeras muestras de una estética del vacío y de la nada se manifestaban con la presencia de lugares vacíos en los lienzos de Paul Cézanne o James Ensor... también en la posterior abstracción de la pintura y la escultura modernas con la finalidad de la autonomía y las tendencias a la desmaterialización entre los años cincuenta y sesenta (en los movimientos del Happening y el Fluxus, entre otras manifestaciones). 
Podemos considerar que son incunables de esta tendencia de invisibilidad y ocultación el salir del cuadro en Marcel Duchamp con su Étant Donnés (1946-1966), una instalación sólo visible a través de un pequeño agujero en una puerta o el vaciamiento del cuadro y el fin profético de la pintura en Ad Reinhardt con sus monocromos cuadros negros: Los Ultimative o Pinturas negras de los años cincuenta y sesenta. También el Erased De Kooning drawing 1953, de Robert Rauschenberg. Aunque podemos considerar una contribución esencial a la desmaterialización del cuadro la de Yves Klein con sus Cuadros espirituales y su interés específico por el vacío: en 1958, en la Galería Iris Clert de París con su exposición inmaterial o cuando entre 1959-62 vendió sus Schecks des Immaterialen

En esta línea, el vacío sigue presente en el contexto del sujeto de la hiper-modernidad. Las ficciones sobre las que se construye están llenas de vacíos. Estos espacios por un lado son consecuencia de unas imágenes sin referencias orientadas a saciar el hambre de sus deseos; y por otro lado constituyen el mismo deterioro y la depresión del sujeto. Ambas orientaciones, tanto la del vacío de la imagen como la del vacío del sujeto, pueden ser corregidas desde la activación y el entendimiento del vacío como una categoría creadora aunque para ello se hace necesario analizar cuáles son los principios del vacío como práctica antivisual.

\section{METODOLOGíA. Organización y jerarquía.}

\section{Claves:}

Hemos definido las claves antivisuales como palabras-objeto relacionadas principalmente con el contexto de la visualidad y la antivisualidad. Así encontramos entre otras: ausencia, enigma, secreto, silencio, misterio, borrado, tapado, tachado, vacío, infinito, oscuridad, experiencia, luz, efímero, inmaterial...

Para clasificar estas claves: hemos seguido el pensamiento de Thomas Munro para quien una obra de arte no está restringida a sus cualidades visuales. En este sentido "visual" sólo se refiere a su forma de exposición al observador, a su contenido expuesto (Munro, 1962). El distingue tres elementos principales, el artista, la obra y el espectador. Nosotros hemos querido sumar a esta clasificación cinco tipologías más dado el interés práctico que perseguimos. La clasificación que hemos propuesto quedaría de la siguiente forma:

- Lo escópico. Frente a la visión objetiva, y al revés de lo que pudiera aparentar, planteamos en este grupo aquellas claves principales centradas en la imposibilidad de la mirada.

- El sujeto creador. Claves relacionadas con la actitud del artista para producir la obra desde una posición de antivisualidad, de negación o de no hacer y un convencimiento por fe, espíritu, juego...

- La producción de obra. Claves que relacionan la antivisualidad con la presentación de obra (en el objeto), la representación (en la imagen), o su ideación (como proyecto de negación en el conjunto).

- El sujeto espectador. Claves que relacionan la antivisualidad con la experiencia en el espectador.

- La alteridad. Claves que relacionan la antivisualidad con el acontecimiento, con lo Real, con lo otro.

- El lugar. Claves que relacionan la antivisualidad con la espacialidad.

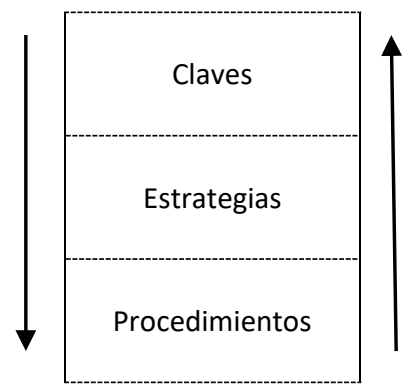

Tabla 2 Clasificación de la práctica antivisual. Fuente propia.

Cualquiera de estos tres elementos puede ocupar jerárquicamente la parte superior del proceso y a su vez actuar de forma que influencien o no al resto que entran en juego. Por ejemplo, una práctica antivisual como un borrado, donde la producción de la obra es clave y que clasificamos como una estrategia de reducción, procedimentalmente se podría producir de muchas formas como por medio de una sustracción o por medio de una superposición. Es posible, que aun siendo la producción del objeto la clave de la obra, sea en el procedimiento donde radica la importancia del proyecto, pasando a ocupar éste, un lugar destacado sobre la clave que lo define. En otros casos, la propia estrategia puede ocupar un lugar destacado. 


\section{Estrategias:}

Son los medios y la ordenación de las claves que permiten al artista conducir a la obra hacia la antivisualidad.

Para clasificar las estrategias hemos seguido el trabajo del investigador Miguel Angel Hernández Navarro que define la negación de la representación como todas aquellas estrategias creativas que producen un distanciamiento entre la realidad y su imagen (HernándezNavarro, 2003).

a) Reducción de lo que hay para ver.

b) Ocultación del objeto visible.

c) Desmaterialización como desaparición de la obra.

\begin{tabular}{|c|c|c|c|c|c|c|}
\hline \multicolumn{3}{|l|}{ REDUCCIÓN } & OCULTACIÓN & \multicolumn{3}{|c|}{ DESMATERIALIZACIÓN } \\
\hline OBJETO & MONOCROMO & TEXTO & TAPAR & INMATERIAL & LUZ & DIFUSO \\
\hline GALERIA & MARCO & LUGAR & TACHAR & CREENCIA & SONIDO & BORRADO \\
\hline NEGATIVO & ESQUEMA & FALTA & INVERTIR & FENÓMENO & DESTRUCCIÓN & CERO \\
\hline ACONTECIMIENTO & ACCIÓN & PROYECTO & SUPERPONER & ACCIÓN & INVISIBLE & AUSENCIA \\
\hline
\end{tabular}

Tabla 3 Tres de las cuatro estrategias principales de la antivisualidad. Fuente propia.

Tres estrategias ya conocidas a las que durante la investigación hemos aportado una nueva:

d) La Resonancia, como reaparición de la imagen a través del vacío. En música, la resonancia musical se refiere a los sonidos elementales que acompañan al principal en una nota musical y comunican un timbre particular a cada voz o instrumento musical. En nuestra investigación entendemos por resonancia las lagunas de la ausencia en la imagen que nos permiten hablar de un referente que no está en la representación pero cuyo eco se hace presente gracias al vacío. En ciertas imágenes el vacío actúa como protagonista remitiendo a una ausencia que está presente en la imagen pero que el espectador puede reconocer. La evidencia es la ausencia reconocida por el espectador en el vacío. Por eso podemos hablar del espectador como resonante.

\section{Procedimientos:}

Son el hacer y la ejecución de la obra material o inmaterial dentro de un sistema antivisual que reuniría el abanico de prácticas artísticas que alejan a la imagen de su representación.

Accidentar, Adicionar, Alentar, Apropiar, Argumentar, Articular, Atar, Ausencia, Azar, Bloquear, Borrar, Cartografiar, Cegar, Clonar, Comparar, Componer, Creer, De-construir, Desarmar, Describir, Descubrir, Desproveer, Desvelar, Embalar, Encolar, Enumerar, Envolver, Escribir, Escuchar, Falsear, Golpear, Graduar, Hesitar, Indiciar, Jugar, Limpiar, Medir, Multiplicar, Ocultar, Ordenar, Precintar, Prensar, Presentar, Proyectar, Publicitar, Quebrar, Quemar, Rastrear, Repetir, Rescatar, Restar, Romper, Saturar, Sellar, Silenciar, Sobre-exponer, Sugerir, Superponer, Sustraer, Tachar, Tapar, Vaciar, Vaporizar, Velar, Yugular...

Tabla 4. Procedimientos antivisuales. Fuente propia.

\section{DESARROLLO. Sistema de estrategias}

\begin{tabular}{|c|c|c|c|}
\hline Reducción & Ocultación & Desmaterialización & Resonancia \\
\hline \multirow{4}{*}{ Tabla 5 Ciclo de retroalimentación en la antivisualidad. Fuente propia. }
\end{tabular}

Recordemos que definimos la negación de la representación como todas aquellas estrategias creativas que producen un distanciamiento entre la realidad y su imagen. Las cuatro estrategias que aparecen en el cuadro superior constituirían un eje que permite pensar el proceso antivisual como un proceso de ida y vuelta en la aparición y desaparición de la imagen. Este eje que va de la materialización a la desmaterialización es un proceso de retroalimentación, fundamental de cara a la relación de la imagen y el sujeto en la actualidad. Las estrategias quedarían del siguiente modo: 
- Reducción de lo que hay para ver.

- Ocultación del objeto visible.

- Desmaterialización como desaparición de la obra.

- La Resonancia como reaparición de la imagen a través del vacío.

Podemos decir que se da por tanto, un ciclo de retroalimentación entre resistencia y subversión de la ausencia en las imágenes, que nos permiten hablar del vacío creador.

Muchas obras de arte, y especialmente, muchas imágenes del mapa de la bidimensionalidad presentan elementos ausentes en sus representaciones. Hasta el momento todas estas representaciones se vinculaban a una suerte de antivisualidad, y de negación en la representación generalizada como posicionamiento de resistencia.

Si aceptamos la existencia de la retroalimentación como un juego entre la ausencia de lo que debería estar presente, y una resonancia de lo que pensamos hace referencia lo ausente, nos encontraríamos con que precisamente esa ausencia juega un valor de bisagra entre la imagen y nuestro imaginario, un juego en definitiva donde la ausencia no es negación, sino significación y apertura, un juego hacia la posibilidad.

Hemos visto que ciertas imágenes contemporáneas, precisamente por su forma de ser elaboradas, tiene precisamente la característica de la falta de un referente original en la realidad. Esto no sería un problema si no fuera porque esta característica coincide con una malograda construcción del sujeto cuando se trata de sus representaciones y a partir de las imágenes surgidas de sus deseos.

\section{DISCUSIÓN Procedimientos para una categoría creadora}

Por tanto, a la hora de analizar el vacío en la representación debemos tener en cuenta sus diferentes caras:

\section{Vacío como resistencia}

Las estrategias artísticas presentes en el régimen de la sombra tienen como punto común un interés por las cosas que desbordan lo visible y lo imperceptible: las discapacidades del ojo, la ceguera, lo háptico, lo audible, lo escondido, el velo, lo mínimo, lo inmaterial, lo infravisible, lo desaparecido... y en definitiva son estrategias donde la protagonista es la ausencia en forma de reducción, ocultación y desmaterialización de lo que hay que ver.

\section{Vacío como subversión}

Hemos observado que estas estrategias que anteriormente cumplían una función de resistencia ante el predominio de lo visual, hoy podemos considerar que están maduras y nos permiten, tras haber realizado una revisión, transformarlas en una gramática del vacío y la subversión. Una Gramática revisada donde la ausencia de la imagen puede incidir en: lo escópico, la producción de obra, el sujeto creador, el sujeto espectador, la alteridad, el lugar, el lenguaje y el objeto. Y en donde en su estructura conviven líneas clave del pasado actualizadas junto a otras nuevas: el monocromo, el no hacer, el objeto, las imágenes ciegas, la propia negación, la negación del lugar, el acontecimiento, la experiencia, lo inmaterial, y la percepción. Incidencias en unos procedimientos al fin, donde el vacío se revaloriza como objeto, galería, tapado, tachadura, inversión, borrado... y que nos hacen reflexionar sobre el vacio como una categoría creadora.

\section{Vacío como Creación}

Por tanto, la resistencia del vacío adquiere un nuevo sentido, no como antivisualidad sino como reducción de lo que hay que ver para un acercamiento al Vacío de posibilidad. Si el vacío se expande mayor cercanía a lo real. Si se reduce mayor cercanía al individuo. Mientras, la subversión, pasaría a ser el acto creador desde el vacío, como inversión de los valores de la resistencia y una puesta en valor de la creatividad desde el vacío. un intento por acercarnos a lo no representable, al evento, a lo no racional, a la idiocia a través del vacío.

\section{CONCLUSIONES. La negación de la representación como estrategia creativa del dividuo}

Hemos considerado el vacío como un concepto espacial que por antítesis a la luz representaba el mundo de la oscuridad, lo no visto y, por tanto, alejado de cualquier forma de conocimiento. Podríamos pensar que en las bellas artes la antivisualidad era consecuencia de 
una resistenca a la verdad y a la razón de la imagen totalizadora de la ciencia y el progreso. Sin embargo, en esta comunicación proponemos que el vacío no debe representar por más tiempo el reflejo de una imagen de resistencia y sí coronarse como una categoría autónoma y en este sentido subversiva. Dentro de los procedimientos artísticos las estrategias de reducción, ocultación, desmaterialización y resonancia permiten hacer del vacío una práctica creadora y constructora no solo de imaginario sino también de identidad. Estas estrategias generan el denominado vacío creador que permiten, por un lado llenar el vacío generado por la pérdida de la identidad, y por otro permiten el reencuentro con la imagen de la sombra que nos pertenece. El vacío creador permite un reencuentro con el espacio situado entre las cosas, con el recuerdo a través de la resonancia, de la memoria de lo que el sujeto es más allá de su apariencia. Sin tocarlo nos acerca al mundo imaginario, al resto de lo que el acontecimiento fue, y por ende, a los fragmentos que se han depositado de su sustancia real. Entendemos que esta práctica sitúa al sujeto como un ente dividido y fragmentado, contrario a toda visión del mundo unitaria y totalizadora, y por tanto, como una realidad frágil pero llena de posibilidades. El vacío creador ofrece la posibilidad al sujeto de transformarse en posibilidad, en acontecimiento. Las estrategias del vacío en el arte son la mecha para la posibilidad de la dividualización, del ser potencia.

\section{FUENTES REFERENCIALES}

Arnheim, R. (1985). El Pensamiento Visual. Paidós Estética. Págs. 101 y ss.

Butin, H. (2009). Diccionario de conceptos de arte contemporáneo. Abada Editores. Págs.96-99.

Dornbuscch, C. (2011). 1989 e as consequências: as representações da ausência no cinema pós-muro. Pandaemoium. 17, 25-49.

Hernández, M. Á. (2003). (La) nada para ver, el procedimiento ceguera del arte contemporáneo. Debats, 82, 56-65.

Krauss, R. (1986). Antivisión. Revista October. 36, 147-154.

Lehmann, U. (2009). Estética de la ausencia. En Butin, H. Diccionario de conceptos de arte contemporáneo. Madrid: Abada Editores.

Lippard, L. (1973). Seis años, la desmaterialización del objeto artístico. Madrid: Akal.

Meana, J. C. (2012). Poéticas de negación de lo visual. Actas do Il Congresso Internacional Criadores Sobre outras Obras - CSO'2011 4-0 (395401).

Munro, T. (1962). La forma en las artes, un panorama de morfología estética. Buenos Aires: Paidós. p. 17. 